\title{
DEVELOPMENT OF CREATIVE QUALITIES OF FUTURE TRANSLATORS IN THE FIELD OF PROFESSIONAL COMMUNICATION IN THE FORMATION OF SOCIAL AND CULTURAL COMPETENCES
}

\author{
Telezhko Irina ${ }^{1}$, Chernova Oxana $^{2}$, Gakova Elena $^{3}$ \\ ${ }^{1}$ Prof., RUDN University, RUSSIA \\ ${ }^{2}$ Prof., RUDN University, RUSSIA \\ ${ }^{3}$ Prof., RUDN University, RUSSIA
}

\begin{abstract}
The subject of the research is the development of profession important qualities of Russian students in the process of formation of socio-cultural competence of the translator in the field of professional communication. Practice shows that future translators face difficulties of socio-cultural nature when translating profession oriented discourse that causes the need to develop creativity in students in the process of formation of socio-cultural competence.

The article analyzes socio-cultural information in the profession oriented discourse in the field of "Oil and gas engineering", the concepts of "creativity", "creative qualities" in Russian and foreign studies are considered, "translator's creativity in the sphere of professional communication" is defined.

On the basis of the research, according to the data of the survey of professional translators, creative qualities of the translator in the field of professional communication were selected. Teaching methods and techniques, aimed at development of translators' creativity as well as the ability to apply in practice sociocultural knowledge and translation skills effectively were defined. The above mentioned strategy improves both the quality of translation of profession oriented discourse and intercultural communication.
\end{abstract}

Keywords: profession oriented translation, sociocultural competence, profession oriented discourse, creativity, creative qualities.

\section{INTRODUCTION}

In modern conditions, the need for highly qualified translators who carry out their activities in the professional sphere is increasing. In this regard, the issue of training professionals providing communication between specialists from different linguocultures is of particular importance.

A translator in the field of professional communication is an expert in a particular subject area, fluent in a foreign language, carrying out intercultural communication in a professional field. The subject of his activities is texts that are traditionally related to the scientific style of speech (in our case, the texts of the oil industry). Translation activity is the realization of the interaction of cognitive and language structures. The translator always faces the problem of perception and processing of someone else's "mental content", because in the translation he does not express his own thoughts, but only verbalizes the ideas formulated by the author in the source text, taking into account the communicative situation in which the translation text will be used. 
The task of the translator is to understand the source text created by a representative of a certain professional group (in our case in German and English speaking countries), in order to create a statement in the native language for Russian specialists, who received an education different from German and English speaking oil industry workers in Russia, based on the understood meaning. The ability of a translator to act as a mediator in the process of communication between representatives of professional communities of different countries is largely determined by the knowledge of the foreign language specialized culture and the ability to compare it with the sociocultural characteristics of communication among specialists in Russia.

The task of familiarizing with a foreign language culture is outlined within the framework of sociocultural competence, which we understand as "the willingness and ability to understand, analyze sociocultural information contained in the source text of the language learned, the ability to compare this knowledge with the recipient's knowledge of the text being translated and to use appropriate translation techniques for adequate transfer in the translation text " [Telezhko, 2018 p. 204].

Thus, the sociocultural competence of a translator in the field of professional communication is one of the fundamental factors and an indispensable condition for obtaining an adequate translation with maximum preservation of the sociocultural specificity of the original text.

The activities of the translator in the oil discourse

A survey of professional translators showed that translation is most common in the oil industry. In this case, the translator faces the solution of complex problems that go beyond the transfer of terminology, due to the variety of styles, themes and types of translated texts: - Scientific and technical (reports on the work performed, project documentation);

- Financial (expense schemes, financial statements, travel documents);

- Legal (materials of contracts, licenses, patents, etc.);

- Publicistic (scientific articles);

- Correspondence.

A distinctive feature of these texts is a very accurate expression of scientific and technical thought. These texts are distinguished by consistency, accuracy of presentation and style of presentation, unambiguity and concreteness in the interpretation of facts, etc. However, it should be emphasized that there are significant sociocultural differences in different linguocultures which are reflected in language.

Analysis of 26 texts in the field of "Oil and gas business" showed: - National realities are often encountered specific words and phrases associated with history, geographical and climatic conditions in a professionally oriented texts in the "Oil and Gas engineering" field; -Concepts (thinking stereotypes, symbols of culture, differences in world views); - Structural and semantic features of linguistic units (images of language, phraseology, speech behavior, code system).

These linguocultural units reflect the linguistic culture of society and act as units of sociocultural information. - In professionally oriented texts, in some cases, the presentation of the material is constructed in a more democratic style than in Russian texts: the inductive method is used; - In the foreign technical documentation on oil and gas development, the sender of the text personally addresses the recipient of the translation text, etc .;

- Non-verbal (paratextual) means are used in foreign language professional communication: digital, letter graphic. These include drawings, illustrations, photographs, tables, graphs, charts, formulas, geological maps, geological relief maps, applications, etc.

When performing a translation a translator should be guided by the principle of preserving national identity as much as possible while complying with the norms and rules of the translation language. The translator transfers from one lingvuoculture to another, while the translation text must comply with the rules of spelling, grammar and the norms of use of the target language, stylistically correspond to the source text. He needs to be able not only to understand the meaning of sociocultural information contained in the source text, but to compare it with existing concepts in Russian, compare, not giving his own estimates, selecting information That is not in the cognitive baggage of the recipient of the translation text, develop a translation strategy, and accurately convey scientific and technical information.

Thus, the translation of problematic communicative situations, socio-cultural realities in professionally oriented texts is an intellectual and cognitive activity that requires creative problem-solving 


\section{CREATIVITY AND CREATIVE QUALITIES}

The definition of creativity is the subject of research, and there are scientific discussions about it. In recent years, the understanding of this term has undergone certain changes both in Russia and abroad. In Russian science, the concept of "creativity" is used by researchers to denote creative thinking, creative process, sometimes as a characteristic of the personality of a creative person, creative abilities [Gakova, 2014]. In foreign studies, creativity is defined as:

- The ability to create a product that is new and at the same time corresponds to the context in which it is located. Such a product can be, for example, an idea, a musical work, a story or an advertisement, therefore, the translation of the text is also a product of the translator's activities;

- A complex system consisting of neural, cognitive, social, emotional and cultural components, manifested in the behavior of the individual. [Amabile, 1996; Lubart, 1994; MacKinnon, 1962; Ochse, 1990; Sternberg \& Lubart, 1995].

According to many authors, creativity is associated with intellectual activity, motivation, creative environment, requires creative thinking from the individual. It is also a group effective activity, in the course of which one gains the ability to quickly create working relationships, resolve conflict situations, effectively interact and exchange knowledge and experience in the course of professional activities. A person can not manage creativity, but he is capable of self-organization and self-actualization, which allowed researchers to consider the motivational orientation in the process of intellectual activity of the individual. Such an approach determines the possibility of developing creative qualities and training them so that the behavior becomes creative.

Based on the above, we define the creativity of a translator in the field of professional communication as the ability of an individual to quickly and efficiently create working relationships, solve problem situations in the professional communication sphere, effectively acquire, apply, and exchange knowledge and experience in the course of professional activity, which will result in a new product - translation text. Researchers of creativity identified more than one hundred creative personality traits. Based on the research, in the course of the experiment conducted at the Department of Foreign Languages of the Engineering Academy of RUDN University, the creative qualities of the translator of professionally oriented texts to carry out effective work were identified. These include the following creative qualities of the personality, which contribute to effective intercultural communication in the professional sphere and effective social and professional activity of future translators of professionally oriented texts: - Adaptability - the ability to adapt to various rapidly changing professional situations and activities;

- Flexibility - the ability to offer various solutions to professional problems;

- Impact - the ability to convince of the correctness of their own judgments;

- Information analysis - the ability to be critical of information;

- Use of technology - the ability to use electronic dictionaries, catalogs, search on the Internet, etc .; - Self-organization - the ability to allocate time, the ability to organize conditions for successful selfproductive

- Teamwork - the ability to effectively interact in a group; activities;

- Systems thinking - the ability to use knowledge systems and skills in solving professional problems [Gakova, 2015].

These creative qualities are important for the translator, as they will help overcome the sociocultural barrier in translating sociocultural information. Therefore, it is necessary to introduce methods and techniques that, when forming sociocultural competence, develop the creative personal qualities of the translator.

\section{TRAINING METHODS AND TECHNIQUES AIMED AT DEVELOPING THE TRANSLATOR'S CREATIVITY}

The development of creativity in the formation of sociocultural competence is carried out at all stages of translation training: professionally oriented, analytical, synthesizing and corrective, using creative methods and teaching methods.

At the professionally oriented stage of education, it is proposed to introduce a special course "Specialized Culture", in which students familiarize themselves with the specifics of professional communication of specialists from a different linguistic community and the need for its comparative analysis with professional communication of specialists in the scientific and technical sphere in Russia and in the country of the studied language. Students develop creative qualities such as adaptability, flexibility, analysis and information 
synthesis.

At the analytical stage of training in learning to perceive and understand the socio-cultural information of the source text, the problem-search method of training and the developed system of analytical exercises are used.

For example, when forming the ability to isolate and analyze language representations of concepts in German oil discourse with a view to their further translation into Russian students are offered an instruction with the help of which they can independently analyze the concept of "Erde" in German texts in the direction of "Oil and Gas Engineering" using information technologies. This method ensures the development of logical and systemic thinking, information analysis, the ability to use electronic dictionaries, catalogs, and search on the Internet.

The synthesizing stage of learning to translate sociocultural information begins with a practical lesson, where the concept of "transformation" (the transformation of a fragment of the original into an appropriate translation) is explained to students. The teacher asks the students to pay attention to the fact that the techniques of transcription, transliteration, tracing are widely used to translate the sociocultural realities, their own names, geographical names, abbreviations, terms; explains cases of deviations from the rule (Freiberg Freiberg, but Schwaben - Schwabia) and suggests performing exercises, the purpose of which is not only to teach methods and methods of translating socio-cultural information, but also the development of creative thinking, for example:

- Exercises on interlanguage paraphrasing (in order to teach how to find equivalents of sociocultural realities that correspond to the Russian speech norms):

- Replace the proposed construction with an adjective, observing the norm of the Russian language; productive (in order to develop the skills and abilities of a specific translation task): - Translate statements from German into Russian, observing the norm of the Russian language;

- Find equivalents for abbreviations using transliteration.

At the synthesizing stage of education, students learn to select equivalents in their native culture to the language representations of concepts, using the case method using the example of the "Ordnung" concept. Acquaintance with the characteristics of the concept "Ordnung" is based on electronic German explanatory dictionaries, electronic dictionaries in the "Oil and Gas Engineering" direction. For comparison with the concept of "order" is used "aligram". Trainees identify conceptual features of the "Ordnung" concept and conceptual features of the "order" concept. Compare them and reveal distinctive conceptual features in German oil discourse. The work is carried out in small groups, during which the following creative qualities are developed: teamwork, flexibility, information analysis and synthesis, adaptability.

At the corrective stage - a case with pre-programmed errors- When working with the case, such qualities develop: adaptability, self-organization, orientation to success.

\section{DIAGNOSTICS OF THE FORMATION OF CREATIVITY IN FUTURE TRANSLATORS IN THE FIELD OF PROFESSIONAL COMMUNICATION}

In order to prove the authenticity and effectiveness of the proposed training, experimental testing was conducted at the Peoples' Friendship University of Russia, under which the formation of creativity among students (21 students) studying in the Oil Business specialty at the lessons on the discipline "Practical course of profession oriented translation".

This test is aimed at studying the creativity and creative thinking of future translators. Investigated abilities: - Adaptability

- Flexibility

- Analysis and synthesis of information

- Teamwork

- Accuracy

The students were offered a specialty text containing socio-cultural information and a test task was given: "Find translation correspondences and equivalents to the selected lexical units. Specify the translation techniques used to estimate the found value of lexical units (adequate / inadequate) ".

At the beginning, each student individually translated the text, drawing on the knowledge gained during the special course "Specialized Culture" and practical exercises. Then, with the help of a teacher, having broken 
up into small groups, students conduct a joint analysis of text translation and problematic communicative situations, isolate sociocultural information, determine methods and techniques for translating sociocultural characteristics, then translate. Students together with the teacher discuss the proposed translation options.

In the course of work, each of the small groups presents their own translation of socio-cultural information, answers questions from participants in other groups and clarifies their own translation version. For our research, in order to reveal the level of students' creativity, the test "Creativity" by N.F. Vishnyakova was used. This test allows you to identify the level of creative abilities. Students were asked to answer a series of questions, to evaluate their personal qualities on their own. Table 1 shows the average values of creativity. The ranking of the average points obtained for each indicator of creativity showed that the most significant indicators of the translator's creativity in the field of professional communication: analysis and synthesis of information, system thinking, adaptability. At the beginning of the experiment, teamwork, the use of technology came first, and systems thinking, precision in fourth position, adaptability, flexibility in sixth position. At the end of the experiment, the systemic thinking index increased to the first position, adaptability, flexibility to the third position. The sum of the average points received for each indicator of creativity increased at the end of the experiment.

The results of the diagnosis of the formation of creativity are shown in Table 1.

Table 1

\begin{tabular}{|l|l|l|l|l|}
\hline \multirow{2}{*}{ Indicators Of Creativity } & \multicolumn{2}{|l|}{$\begin{array}{l}\text { At the beginning of the } \\
\text { experiment }\end{array}$} & At the end of the experiment \\
\cline { 2 - 5 } & Average & Rank & Average & Rank \\
\hline $\begin{array}{l}\text { Analysis And Synthesis Of } \\
\text { Information }\end{array}$ & 6,9 & 2 & 7,6 & 2 \\
\hline Adaptability & 6,5 & 6 & 7,4 & 3 \\
\hline Flexibility & 6,5 & 6 & 7.4 & 3 \\
\hline System Thinking & 6,7 & 4 & 8,4 & 1 \\
\hline Accuracy & 6,7 & 4 & 7,4 & 3 \\
\hline Self-Organization & 6,55 & 6 & 7,0 & 6 \\
\hline Impact & 6,8 & 5 & 7,2 & 5 \\
\hline Use Of Technology & 6,9 & 2 & 7,3 & 4 \\
\hline Teamwork & 7,0 & 60,55 & 66,7 & 6 \\
\hline Amount & 6,0 & & 3 \\
\hline
\end{tabular}

More than half of the students showed a reliably high result $(58.7 \%)$ in terms of "system thinking" and "analysis and synthesis of information originality" and "creative attitude", students also tend to develop adaptability and flexibility (37.9\%).

Thus, the proposed methods and techniques are aimed at developing the translator's creativity as professionally important qualities, as well as the ability to effectively apply sociocultural knowledge and translation skills in practice, which contributes to the quality of translation of professionally oriented texts and 
the successful implementation of intercultural communication.

\section{REFERENCE LIST}

1. Telezhko I.V. Translation didactics: traditions and innovations. // Collective monograph.-Moscow, Ed. Flint, 2018.-223 p.

2. N.N. Gavrilenko, I.V. Telezhko Professionally Oriented Textile Socio-Cultural Competency // The MiddleEast Journal of Scientific Research. Volume 21 Number (2) 2014. - R. 362-367, 2014. http://idosi.org/mejsr/ mejsr21\% 282\% 2914.htm (ISSN 1990-9233 @ IDOSI Publications, 2014 DOI: 10.5829 / idosi.mejsr.2014.21.02.2.21292)

3. Gakova. E.V. Creativity as a complex behavioral construct // European Sosial Science Journal. 2014. - № 9.- Volume 1.

4. Gakova E.V. Formation and development of creative competencies of future translators of professionally oriented texts // Modern problems of science and education. M, - 2015., № 1

5. Telezhko I.V., Gakova E.V. On the development of creative personality traits of students in the formation of the socio-cultural competence of future translators of profession oriented texts // Collection of articles of the VIII International Scientific Conference "Actual Problems of Linguistics and Linguodidactics of the Foreign Language of Business and Professional Communication". Moscow, RPFU, -2018, p. 154.

6. Litvinov A., Breus E., Volkova Z., Chernova O.. Translational studies and methods of teaching translation. In the collection of EDUlearn16th Proceedings. 8th International Conference on Education and New Learning Technologies, 4-6th July, 2016. Barcelona, Spain.

7. Amabile, T. M. Motivation and Creativity: Motivational Orientation on Creative Writers // Journal of Personality and Social Psychology. - 1985. - Vol.48. - № 2. - P.393-399.

8. Boyatzis, R.E. Competencies in the 21st century. // Journal of Management Development. - 2008. - Vol. 27. - №. 1. - P. 5-12.

9. Csikszentmihalyi, M. Edited extract from R. Sternberg's Handbook of Creativity. Cambridge: Cambridge University Press, 1999. - P. 313-35.

10. Gardner, H. Creating an Anatomy of Creativity Seen Through the Lives of Freud, Einstein, Picasso, Stravinsky, Eliot, Graham, and Ghandi, New York (1993), New York, 1993. - 464 p.

11. Guilford, J.P. Creativity // American Psychologist. - 1950. - V. 5. - Issue 9, - P. 444-454.

12. Lubart, T. The generality-specificity of creativity: a multivariate approach / T. Lubart, J.-H. Guignard // Creativity: from potential to realization / R. J. Sternberg, E.L. Grigorenko, J.L.Singer. Washington: American Psychological Association, 2004. - P. 43-56.

13. Sternberg, R. J. The Nature of Creativity // Creativity Research Journal, 2006. - Vol. 18. - №. 1. - P. 8798. 